\title{
Association of genetic variants of the $\alpha$-kinase 1 gene with type 2 diabetes mellitus in a longitudinal population-based genetic epidemiological study
}

\author{
YOSHIJI YAMADA ${ }^{1,2}$, KOTA MATSUI ${ }^{2,3}$, ICHIRO TAKEUCHI $^{2,3}$, MITSUTOSHI OGURI $^{4}$ and TETSUO FUJIMAKI $^{5}$ \\ ${ }^{1}$ Department of Human Functional Genomics, Life Science Research Center, Mie University, Tsu, Mie 514-8507; \\ ${ }^{2}$ Core Research for Evolutional Science and Technology, Japan Science and Technology Agency, Tokyo 102-0076; \\ ${ }^{3}$ Department of Scientific and Engineering Simulation, Graduate School of Engineering, Nagoya Institute of Technology, \\ Nagoya, Aichi 466-8555; ${ }^{4}$ Department of Cardiology, Japanese Red Cross Nagoya First Hospital, Nagoya, \\ Aichi 453-8511; ${ }^{5}$ Department of Cardiovascular Medicine, Inabe General Hospital, Inabe, Mie 511-0428, Japan
}

Received January 30, 2015; Accepted February 6, 2015

DOI: $10.3892 /$ br.2015.439

\begin{abstract}
Previously, our studies identified nine genes and the chromosomal region $3 \mathrm{q} 28$ as susceptibility loci for myocardial infarction, ischemic stroke or chronic kidney disease in individuals by genome-wide or candidate gene association studies. The present study examined the possible association of 13 polymorphisms at these 10 loci with the prevalence of type 2 diabetes mellitus (DM) in community-dwelling individuals. Study subjects comprised 6,027 individuals (797 subjects with type $2 \mathrm{DM}$ and 5,230 controls) who were recruited to the Inabe Health and Longevity Study, a longitudinal genetic epidemiological study of atherosclerotic, cardiovascular and metabolic diseases. The subjects were recruited from individuals who visited for an annual health checkup and they were followed up each year (mean follow-up, 5 years). Longitudinal analysis with a generalized estimating equation and with adjustment for age, gender and body mass index (BMI) revealed that $\mathrm{rs} 2116519(\mathrm{C} \rightarrow \mathrm{T})$ of $F A M 78 B(\mathrm{P}=0.0188)$, as well as rs2074379 $(\mathrm{G} \rightarrow \mathrm{A}, \mathrm{P}=0.0121)$ and $\mathrm{rs} 2074388(\mathrm{~A} \rightarrow \mathrm{G}$, $\mathrm{P}=0.0053)$ of $A L P K 1$ were significantly $(\mathrm{P}<0.05)$ associated with the prevalence of type $2 \mathrm{DM}$. Longitudinal analysis with a generalized linear mixed-effect model and with adjustment for age, gender and BMI among all the individuals revealed that rs2116519, rs2074379 and rs2074388 were significantly associated with fasting plasma glucose level $(\mathrm{P}=0.0352$, 0.0017 and 0.0010 , respectively) and to blood glycosylated hemoglobin (hemoglobin $\mathrm{A}_{1 \mathrm{c}}$ ) content $(\mathrm{P}=0.0065,0.0090$ and 0.0079 , respectively). Similar analysis among individuals
\end{abstract}

Correspondence to: Professor Yoshiji Yamada, Department of Human Functional Genomics, Life Science Research Center, Mie University, 1577 Kurima-machiya, Tsu, Mie 514-8507, Japan E-mail: yamada@gene.mie-u.ac.jp

Key words: type 2 diabetes mellitus, genetics, polymorphism, genetic epidemiology, longitudinal study not taking antidiabetic medication revealed that rs2074379 and rs2074388 were associated with the fasting plasma glucose level ( $\mathrm{P}=0.0073$ and 0.0042 , respectively) and blood hemoglobin $\mathrm{A}_{1 \mathrm{c}}$ content ( $\mathrm{P}=0.0142$ and 0.0126 , respectively), whereas rs2116519 was associated with blood hemoglobin $\mathrm{A}_{1 \mathrm{c}}$ content only $(\mathrm{P}=0.0470)$. ALPK1 may thus be a susceptibility gene for type $2 \mathrm{DM}$.

\section{Introduction}

The prevalence of type 2 diabetes mellitus (DM) is increasing rapidly worldwide, with $>170$ million individuals currently affected $(1,2)$ and 439 million adults $(7.7 \%$ of all adults) predicted to be affected by 2030 (2). The major site of this emerging epidemic is expected to be Asia, mainly as a result of changes in nutrition and other lifestyle factors (3). Given that type $2 \mathrm{DM}$ increases the risk for cardiovascular disease and long-term mortality, the health care burden imposed by this condition is a matter of urgent concern (4,5). Aggressive strategies for disease prevention and early detection will be key to tackling this global issue. Approximately $95 \%$ of patients with DM have type $2 \mathrm{DM}$, with characteristics that range from insulin resistance with relatively minor insulin deficiency to insulin deficiency with relatively minor insulin resistance (6). The several mechanisms that have been suggested for the pathogenesis of type $2 \mathrm{DM}$ include an increase in the production of nonesterified fatty acids, inflammatory cytokines or adipokines, and dysfunction of mitochondria for insulin resistance and glucotoxicity, lipotoxicity and amyloid formation for $\beta$-cell dysfunction (1). Although a sedentary lifestyle and overeating appear to be triggering factors, genetic factors are also indicated in the pathogenesis of type $2 \mathrm{DM}$, as a positive family history is associated with a 2.4-fold increase in the risk $(1,7)$.

Previous genome-wide association studies (GWASs) have indicated numerous loci and genes in the predisposition to type $2 \mathrm{DM}$ in various ethnic groups (8-17). Although $K C N Q 1(13,14)$ and UBE2E2 $(15)$ were identified as susceptibility genes for type $2 \mathrm{DM}$ in Japanese individuals, the 
genes that contribute to genetic susceptibility to this condition remain to be identified.

Our previous studies identified nine genes and chromosomal region $3 q 28$ as susceptibility loci for myocardial infarction, ischemic stroke or chronic kidney disease in Japanese individuals by genome-wide (18-20) or candidate gene (21-23) association studies. As type $2 \mathrm{DM}$ is an important risk factor for these diseases (24-26), we hypothesized that certain single-nucleotide polymorphisms (SNPs) at these 10 loci may contribute to the genetic susceptibility by affecting the susceptibility to type $2 \mathrm{DM}$. The present study examined the possible association of 13 SNPs at the 10 loci with the prevalence of type $2 \mathrm{DM}$ in community-dwelling Japanese individuals.

\section{Materials and methods}

Study population. Study subjects comprised 6,027 community-dwelling individuals (797 subjects with type $2 \mathrm{DM}$ and 5,230 controls) who were recruited to a population-based cohort study (Inabe Health and Longevity Study) in Inabe (Mie, Japan). The Inabe Health and Longevity Study is a longitudinal genetic epidemiological study of atherosclerotic, cardiovascular and metabolic diseases (27-33). Detailed methods for recruitment of study subjects and collection of medical examination data were described previously (27).

Individuals with DM were defined as those with a fasting plasma glucose concentration of $\geq 126 \mathrm{mg} / \mathrm{dl}(6.93 \mathrm{mmol} / \mathrm{l})$, with a blood glycosylated hemoglobin (hemoglobin $\mathrm{A}_{1 \mathrm{c}}$ ) content of $\geq 6.5 \%$, or who were taking antidiabetic medication. Type 2 DM was defined according to the criteria accepted by the World Health Organization and described previously $(6,34)$. Individuals with type $1 \mathrm{DM}$, maturity-onset diabetes of the young, DM associated with mitochondrial diseases or single-gene disorders, pancreatic diseases, including severe pancreatitis and pancreatic tumors, or other metabolic or endocrinological diseases were excluded from the study. Individuals taking drugs that cause secondary DM were also excluded. Control individuals had a fasting plasma glucose level of $<110 \mathrm{mg} / \mathrm{dl}(6.05 \mathrm{mmol} / \mathrm{l})$, a blood hemoglobin $\mathrm{A}_{1 \mathrm{c}}$ content of $<6.2 \%$ and no history of DM or of taking antidiabetic medication.

The study protocol complied with the Declaration of Helsinki and was approved by the Committees on the Ethics of Human Research of Mie University Graduate School of Medicine and Inabe General Hospital (Mie, Japan). Written informed consent was obtained from all the subjects.

Selection and genotyping of polymorphisms. The 13 SNPs examined in the present study were selected from our previous genome-wide (18-20) or candidate gene (21-23) association studies and were described previously (27). Wild-type (ancestral) and variant alleles of the SNPs were determined from the SNP database (dbSNP, National Center for Biotechnology Information, Bethesda, MD, USA; http://www.ncbi.nlm.nih. gov/SNP).

Venous blood $(5 \mathrm{ml})$ was collected into tubes containing $50 \mathrm{mmol} / \mathrm{l}$ ethylenediaminetetraacetic acid (disodium salt), peripheral blood leukocytes were isolated and genomic DNA was extracted from these cells with a DNA extraction kit
(SMITEST EX-R\&D; Medical and Biological Laboratories, Co., Ltd., Nagoya, Japan). Genotypes of the 13 SNPs were determined at G\&G Science Co., Ltd., (Fukushima, Japan) by a method that combines the polymerase chain reaction and sequence-specific oligonucleotide probes with suspension array technology (Luminex Corp., Austin, TX, USA). Primers, probes and other conditions for genotyping of SNPs examined in the present study were described previously (27), as was the detailed genotyping methodology (35).

Statistical analysis. Quantitative data were compared between subjects with type $2 \mathrm{DM}$ and controls using the unpaired Student's t-test. Categorical data were compared with the $\chi^{2}$ test. The associations of 13 SNPs to the prevalence of type 2 $\mathrm{DM}$, to fasting plasma glucose level or blood hemoglobin $\mathrm{A}_{1 \mathrm{c}}$ content were examined in a 5-year longitudinal cohort study. Longitudinal changes in the prevalence of type $2 \mathrm{DM}$ were compared between the two groups (dominant or recessive genetic model) by a generalized estimating equation (36) and with adjustment for age, gender and body mass index (BMI). Longitudinal changes in fasting plasma glucose level or blood hemoglobin $\mathrm{A}_{1 \mathrm{c}}$ content in all the individuals or in individuals not taking antidiabetic medication were compared between the two groups (dominant or recessive model) in a generalized linear mixed-effect model (37) with adjustment for age, gender and BMI. Age-related changes in the prevalence of type $2 \mathrm{DM}$ or in fasting plasma glucose level or blood hemoglobin $A_{1 c}$ content were estimated with quadratic curves controlling for the observation year. $\mathrm{P}<0.05$ was considered to indicate a statistically significant difference. Statistical analysis was performed with R software version 3-0-2 (The R Project for Statistical Computing) and JMP Genomics version 6.0 (SAS Institute, Inc., Cary, NC, USA).

\section{Results}

Subject characteristics. Characteristics of subjects with type 2 DM and controls in the cross-sectional analysis in March 2014 are shown in Table I. Age, the frequency of males and BMI were significantly greater in subjects with type 2 DM compared to the controls.

Associations with type 2 DM. The associations of the 13 SNPs to the prevalence of type $2 \mathrm{DM}$ were analyzed with a generalized estimating equation and with adjustment for age, gender and BMI (Table II). The rs2116519 $(\mathrm{C} \rightarrow \mathrm{T}) \mathrm{SNP}$ of the FAM78B gene (recessive model), as well as $\mathrm{rs} 2074379(\mathrm{G} \rightarrow \mathrm{A}$, dominant model $)$ and rs2074388 (A $\rightarrow \mathrm{G}$, dominant model) of $A L P K 1$ were significantly $(\mathrm{P}<0.05)$ associated with the prevalence of type 2 DM.

The associations between the prevalence of type 2 DM and age analyzed longitudinally with a generalized estimating equation according to SNP genotype are shown in Fig. 1. The prevalence of type $2 \mathrm{DM}$ was greater in subjects with the $C C$ genotype of rs 2116519 of FAM78B compared to the combined group of subjects with the $T T$ or $T C$ genotypes from 40 to 90 years of age (Fig. 1A), in the combined group of subjects with the $A G$ or $G G$ genotypes of rs2074379 of $A L P K 1$ compared to those with the $A A$ genotype (Fig. 1B) and in the combined group of subjects with the $A G$ or $G G$ genotypes of 
Table I. Characteristics of the subjects with type 2 diabetes mellitus and controls: Cross-sectional analysis in March 2014.

\begin{tabular}{|c|c|c|c|}
\hline Parameter & Diabetes mellitus (n) & Controls (n) & P-value \\
\hline No. of subjects & 797 & 5230 & \\
\hline Age, years & $61.9 \pm 10.5(797)$ & $53.0 \pm 12.9(5230)$ & $<0.0001$ \\
\hline Gender, \% (male/female) & $70.5 / 29.5(797)$ & $53.3 / 46.7(5230)$ & $<0.0001$ \\
\hline Height, cm & $162.6 \pm 9.7(760)$ & $162.5 \pm 9.1(5194)$ & 0.7605 \\
\hline Weight, kg & $64.6 \pm 13.5(758)$ & $60.4 \pm 11.8(5194)$ & $<0.0001$ \\
\hline Body mass index, $\mathrm{kg} / \mathrm{m}^{2}$ & $24.3 \pm 3.9(758)$ & $22.8 \pm 3.3(5194)$ & $<0.0001$ \\
\hline Waist circumference, $\mathrm{cm}$ & $84.9 \pm 9.9(683)$ & $79.8 \pm 9.0(4922)$ & $<0.0001$ \\
\hline Alcohol drinking, $\%$ & $50.2(797)$ & $48.0(5230)$ & 0.2437 \\
\hline Current or former smoking, $\%$ & $55.5(797)$ & $44.2(5230)$ & $<0.0001$ \\
\hline Systolic blood pressure, $\mathrm{mmHg}$ & $127 \pm 18(753)$ & $120 \pm 16(5192)$ & $<0.0001$ \\
\hline Diastolic blood pressure, $\mathrm{mmHg}$ & $77 \pm 12(753)$ & $74 \pm 12(5192)$ & $<0.0001$ \\
\hline Mean blood pressure, $\mathrm{mmHg}$ & $94 \pm 13(753)$ & $89 \pm 12(5192)$ & $<0.0001$ \\
\hline Ocular tension, right, $\mathrm{mmHg}$ & $14.1 \pm 3.2(246)$ & $13.4 \pm 2.9(1815)$ & 0.0005 \\
\hline Functional vital capacity, 1 & $3.14 \pm 0.78(255)$ & $3.32 \pm 0.81(1988)$ & 0.0009 \\
\hline FEV1\% & $80.4 \pm 6.3(255)$ & $81.4 \pm 6.6(1988)$ & 0.0287 \\
\hline Serum albumin, g/l & $44.1 \pm 3.6(613)$ & $44.7 \pm 2.5(3599)$ & $<0.0001$ \\
\hline Serum total cholesterol, $\mathrm{mmol} / \mathrm{l}$ & $5.10 \pm 1.00(784)$ & $5.23 \pm 0.87(5166)$ & 0.0001 \\
\hline Serum triglycerides, mmol/1 & $1.49 \pm 1.06(772)$ & $1.23 \pm 0.82(5164)$ & $<0.0001$ \\
\hline Serum HDL-cholesterol, mmol/1 & $1.51 \pm 0.42(771)$ & $1.68 \pm 0.45(5163)$ & $<0.0001$ \\
\hline Serum LDL-cholesterol, mmol/1 & $3.13 \pm 0.87(770)$ & $3.18 \pm 0.79(5162)$ & 0.1294 \\
\hline Fasting plasma glucose, mg/dl & $132.4 \pm 40.3(789)$ & $95.8 \pm 8.6(5167)$ & $<0.0001$ \\
\hline Blood hemoglobin $\mathrm{A}_{1 \mathrm{c}}, \%$ & $6.65 \pm 1.27(621)$ & $5.54 \pm 0.33(3842)$ & $<0.0001$ \\
\hline Blood urea nitrogen, mmol/1 & $6.27 \pm 3.48(612)$ & $5.03 \pm 1.54(3489)$ & $<0.0001$ \\
\hline Serum creatinine, $\mu \mathrm{mol} / 1$ & $109.5 \pm 182.9(767)$ & $68.3 \pm 45.3(4809)$ & $<0.0001$ \\
\hline $\mathrm{eGFR}, \mathrm{ml} \mathrm{min}{ }^{-1} 1.73 \mathrm{~m}^{-2}$ & $71.2 \pm 23.6(767)$ & $77.5 \pm 15.2(4809)$ & $<0.0001$ \\
\hline Serum uric acid, $\mu \mathrm{mol} / 1$ & $340 \pm 84(759)$ & $324 \pm 86(4772)$ & $<0.0001$ \\
\hline Serum C-reactive protein, $\mu \mathrm{g} / 1$ & $2515 \pm 14479(295)$ & $981 \pm 3758(1818)$ & 0.0001 \\
\hline White blood cells, $10^{3} / \mu 1$ & $5.90 \pm 2.19(554)$ & $5.31 \pm 1.57(4053)$ & $<0.0001$ \\
\hline Red blood cells, $10^{4} / \mu 1$ & $438 \pm 50(556)$ & $437 \pm 44(4067)$ & 0.4542 \\
\hline Hemoglobin, g/l & $139 \pm 18(556)$ & $138 \pm 15(4067)$ & 0.0549 \\
\hline Hematocrit, \% & $40.6 \pm 4.8(555)$ & $40.2 \pm 4.2(4063)$ & 0.0656 \\
\hline Platelets, $10^{4} / \mu 1$ & $21.0 \pm 5.9(551)$ & $22.5 \pm 5.3(4017)$ & $<0.0001$ \\
\hline
\end{tabular}

Quantitative data are mean \pm standard deviation. FEV1, forced expiratory volume in $1 \mathrm{sec}$; HDL, high-density lipoprotein; LDL, low-density lipoprotein; eGFR, estimated glomerular filtration rate $\left(\mathrm{ml} \mathrm{min}^{-1} 1.73 \mathrm{~m}^{-2}\right)=194 \mathrm{x}$ [age (years) $]^{-0.287} \mathrm{x}[\text { serum creatinine }(\mathrm{mg} / \mathrm{dl})]^{-1.094} \mathrm{x}[0.739 \mathrm{if}$ female].
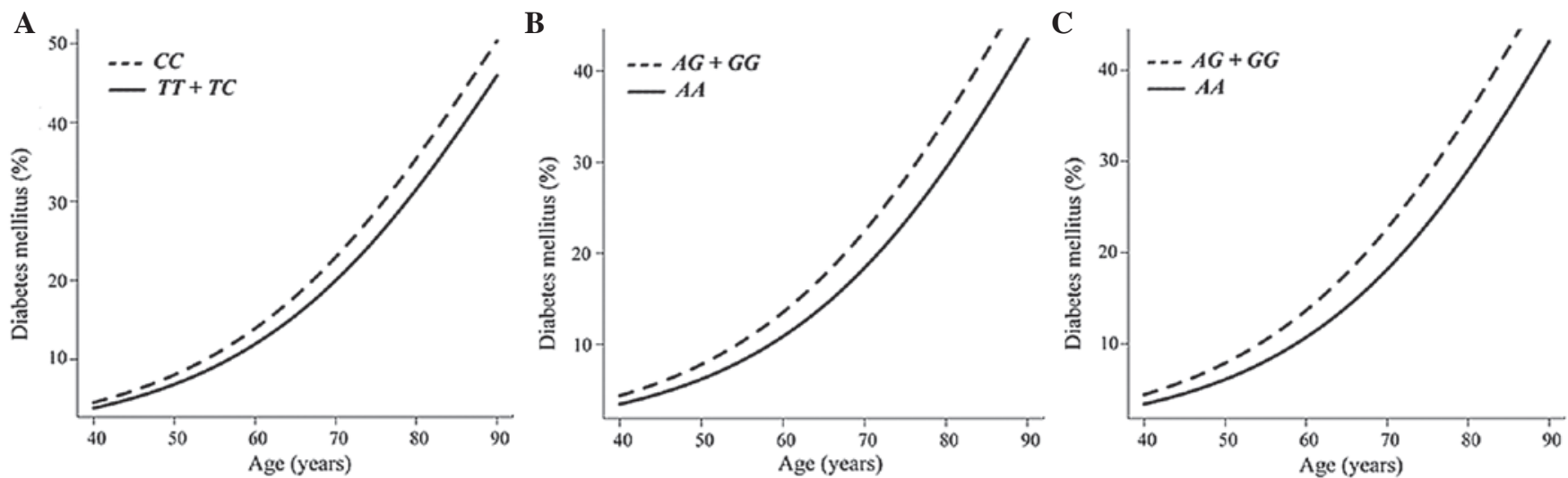

Figure 1. Longitudinal analysis of the associations between the prevalence of type 2 diabetes mellitus and age according to the genotype for (A) rs2116519 of $F A M 78 B(T T+T C$ vs. $C C)$, (B) rs2074379 of $A L P K 1$ ( $A A$ vs. $A G+G G)$ or (C) rs2074388 of $A L P K 1(A A$ vs. $A G+G G)$, with a generalized estimating equation. 
Table II. Associations of polymorphisms with type 2 diabetes mellitus analyzed for 5-year longitudinal data with a generalized estimating equation.

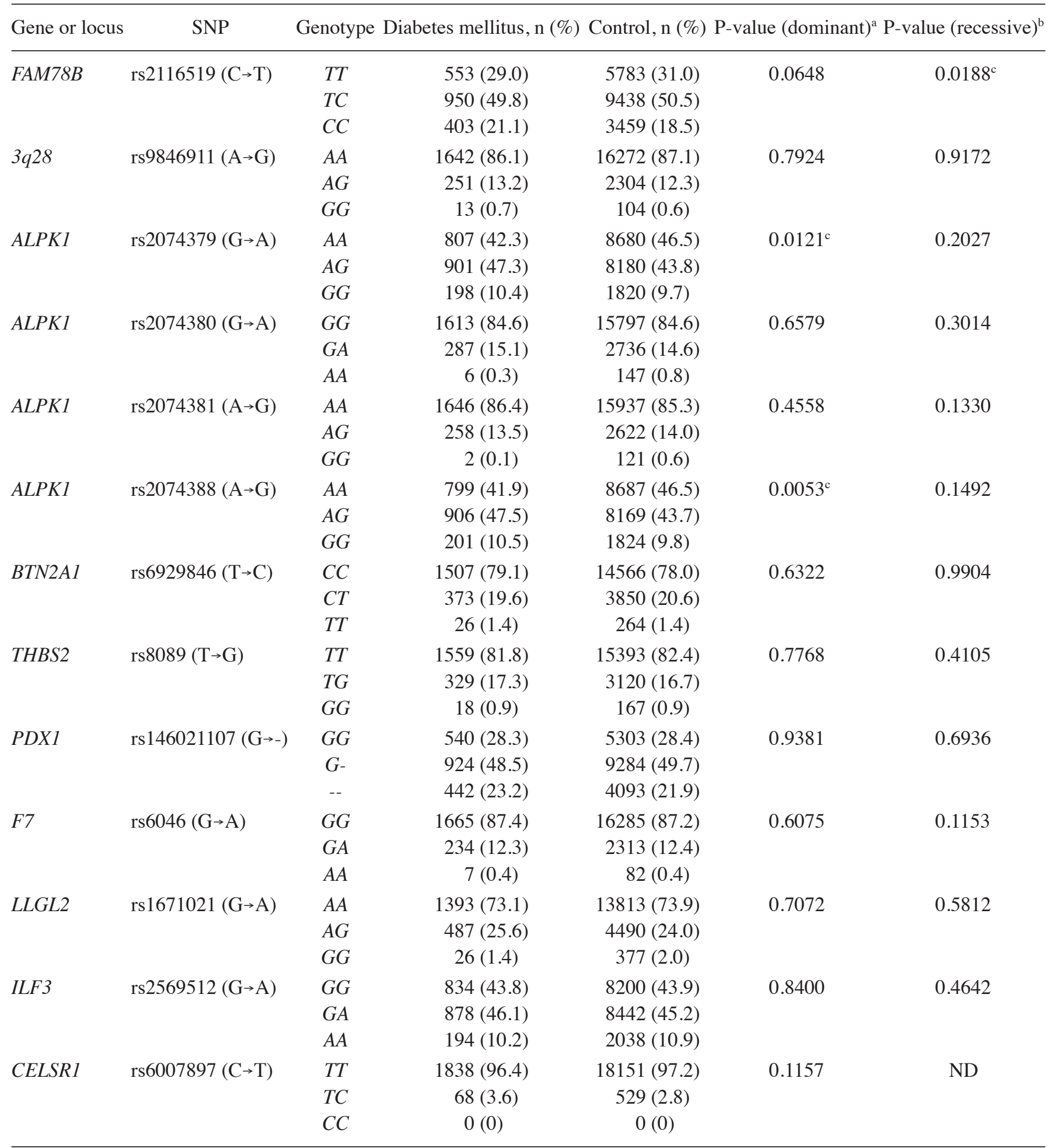

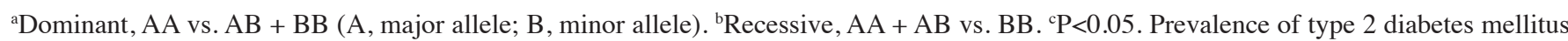
was compared between two groups (dominant or recessive model) for each polymorphism with adjustment for age, gender and body mass index. SNP, single-nucleotide polymorphism; ND, not determined.

rs2074388 of $A L P K 1$ compared to those with the $A A$ genotype (Fig. 1C).

As three SNPs were significantly associated with type 2 $\mathrm{DM}$, the associations of these SNPs to fasting plasma glucose level or blood hemoglobin $\mathrm{A}_{1 \mathrm{c}}$ content in all the individuals or individuals not taking antidiabetic medication were analyzed with a generalized linear mixed-effect model and with adjustment for age, gender and BMI (Table III). The rs2116519 SNP 
Table III. Associations of polymorphisms to fasting plasma glucose level or blood hemoglobin $\mathrm{A}_{1 \mathrm{c}}$ content in all individuals or individuals not taking antidiabetic medication, analyzed for 5-year longitudinal data with a generalized linear mixed-effect model.

\begin{tabular}{|c|c|c|c|c|c|c|}
\hline \multirow{2}{*}{$\begin{array}{l}\text { Gene (SNP) } \\
\text { All individuals }\end{array}$} & \multicolumn{2}{|c|}{ Dominant model $^{\mathrm{a}}$} & \multirow[t]{2}{*}{ P-value } & \multicolumn{2}{|c|}{ Recessive model $^{\mathrm{a}}$} & \multirow[t]{2}{*}{ P-value } \\
\hline & & & & & & \\
\hline$F A M 78 B(\mathrm{rs} 2116519, \mathrm{C} \rightarrow \mathrm{T})$ & $T T(6336)$ & $T C+C C(14250)$ & & $T T+T C(16724)$ & $C C(3862)$ & \\
\hline Fasting plasma glucose, mg/dl & $99.9 \pm 16.4$ & $100.5 \pm 18.3$ & $0.0352^{\mathrm{b}}$ & $100.3 \pm 17.5$ & $100.5 \pm 19.0$ & 0.2251 \\
\hline Blood hemoglobin $\mathrm{A}_{1 \mathrm{c}}, \%$ & $5.69 \pm 0.59$ & $5.71 \pm 0.65$ & $0.0065^{\mathrm{b}}$ & $5.70 \pm 0.63$ & $5.70 \pm 0.66$ & 0.4079 \\
\hline$A L P K 1(\mathrm{rs} 2074379, \mathrm{G} \rightarrow \mathrm{A})$ & $A A(9484)$ & $A G+G G(11099)$ & & $A A+A G(18568)$ & $G G(2018)$ & \\
\hline Fasting plasma glucose, mg/dl & $99.8 \pm 15.7$ & $100.8 \pm 19.4$ & $0.0017^{\mathrm{b}}$ & $100.3 \pm 17.6$ & $101.0 \pm 19.0$ & 0.5509 \\
\hline Blood hemoglobin $\mathrm{A}_{1 \mathrm{c}}, \%$ & $5.68 \pm 0.57$ & $5.72 \pm 0.69$ & $0.0090^{\mathrm{b}}$ & $5.70 \pm 0.62$ & $5.74 \pm 0.73$ & 0.0502 \\
\hline$A L P K 1(\mathrm{rs} 2074388, \mathrm{~A} \rightarrow \mathrm{G})$ & $A A(9486)$ & $A G+G G(11100)$ & & $A A+A G(18561)$ & $G G(2025)$ & \\
\hline Fasting plasma glucose, mg/dl & $99.8 \pm 15.6$ & $100.8 \pm 19.4$ & $0.0010^{\mathrm{b}}$ & $100.3 \pm 17.6$ & $101.2 \pm 19.1$ & 0.4149 \\
\hline Blood hemoglobin $\mathrm{A}_{1 \mathrm{c}}, \%$ & $5.68 \pm 0.57$ & $5.72 \pm 0.69$ & $0.0079^{b}$ & $5.70 \pm 0.62$ & $5.74 \pm 0.73$ & 0.0417 \\
\hline \multicolumn{7}{|l|}{$\begin{array}{l}\text { Individuals without } \\
\text { antidiabetic medication }\end{array}$} \\
\hline$F A M 78 B,($ rs2116519, C $\rightarrow \mathrm{T})$ & $T T(6260)$ & $T C+C C(14045)$ & & $T T+T C(16495)$ & $C C(3810)$ & \\
\hline Fasting plasma glucose, mg/dl & $99.6 \pm 15.8$ & $100.0 \pm 17.2$ & 0.1087 & $99.8 \pm 16.6$ & $99.9 \pm 17.6$ & 0.2482 \\
\hline Blood hemoglobin $\mathrm{A}_{1 \mathrm{c}}, \%$ & $5.68 \pm 0.57$ & $5.69 \pm 0.61$ & $0.0470^{\mathrm{b}}$ & $5.68 \pm 0.60$ & $5.68 \pm 0.62$ & 0.3992 \\
\hline$A L P K 1,($ rs2074379, G $\rightarrow \mathrm{A})$ & $A A(9370)$ & $A G+G G(10935)$ & & $A A+A G(18318)$ & $G G(1987)$ & \\
\hline Fasting plasma glucose, mg/dl & $99.4 \pm 15.0$ & $100.2 \pm 18.1$ & $0.0073^{\mathrm{b}}$ & $99.8 \pm 16.6$ & $100.5 \pm 18.3$ & 0.5845 \\
\hline Blood hemoglobin $\mathrm{A}_{1 \mathrm{c}}, \%$ & $5.66 \pm 0.54$ & $5.70 \pm 0.65$ & $0.0142^{\mathrm{b}}$ & $5.68 \pm 0.59$ & $5.72 \pm 0.71$ & 0.1134 \\
\hline$A L P K 1,(\mathrm{rs} 2074388, \mathrm{~A} \rightarrow \mathrm{G})$ & $A A(9369)$ & $A G+G G(10936)$ & & $A A+A G(18311)$ & $G G(1994)$ & \\
\hline Fasting plasma glucose, mg/dl & $99.4 \pm 15.0$ & $100.3 \pm 18.2$ & $0.0042^{\mathrm{b}}$ & $99.8 \pm 16.6$ & $100.6 \pm 18.3$ & 0.4372 \\
\hline Blood hemoglobin $\mathrm{A}_{1 \mathrm{c}}, \%$ & $5.66 \pm 0.54$ & $5.70 \pm 0.65$ & $0.0126^{\mathrm{b}}$ & $5.68 \pm 0.59$ & $5.72 \pm 0.71$ & 0.0947 \\
\hline
\end{tabular}

${ }^{a}$ Values in parentheses are numbers of measurements. ${ }^{\mathrm{b}} \mathrm{P}<0.05$. Data for fasting plasma glucose level and blood hemoglobin $\mathrm{A}_{1 \mathrm{c}}$ content are means \pm standard deviation. Fasting plasma glucose level and blood hemoglobin $\mathrm{A}_{1 \mathrm{c}}$ content were compared between two groups (dominant or recessive model) for each polymorphism with adjustment for age, gender and body mass index. SNP, single-nucleotide polymorphism.
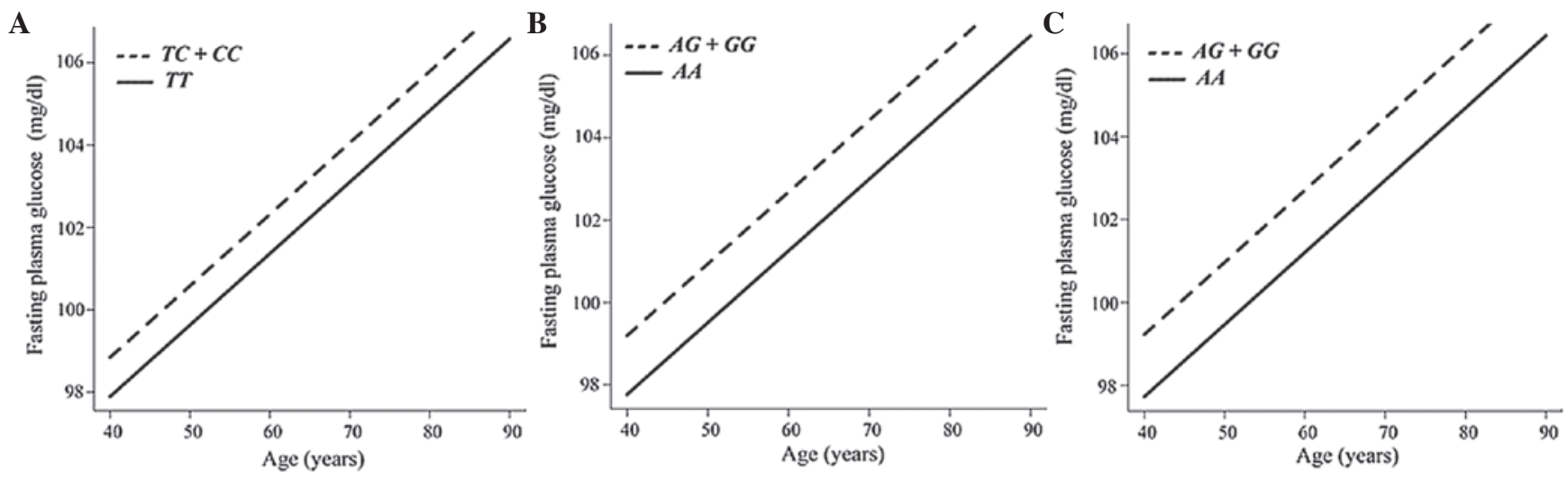

Figure 2. Longitudinal analysis of the associations between fasting plasma glucose level and age according to the genotype for (A) rs2116519 of $F A M 78 B$ $(T T+T C$ vs. $C C)$, (B) rs2074379 of $A L P K 1(A A$ vs. $A G+G G)$ or $(C)$ rs2074388 of $A L P K 1(A A$ vs. $A G+G G)$, with a generalized linear mixed-effect model among all the individuals.

of $F A M 78 B$, as well as rs2074379 and rs2074388 of $A L P K 1$ were significantly $(\mathrm{P}<0.05)$ associated with fasting plasma glucose level and blood hemoglobin $\mathrm{A}_{1 \mathrm{c}}$ content in a dominant model among all the individuals. Among individuals not taking antidiabetic medication, rs2116519 of FAM78B was significantly associated with blood hemoglobin $\mathrm{A}_{1 \mathrm{c}}$ content in a dominant model, whereas rs2074379 and rs2074388 of ALPK1 were significantly associated with fasting plasma glucose level and blood hemoglobin $\mathrm{A}_{1 \mathrm{c}}$ content in a dominant model.

The associations between fasting plasma glucose level and age analyzed longitudinally according to genotype in all the individuals with a generalized linear mixed-effect model are shown in Fig. 2. Fasting plasma glucose level was greater in the combined group of individuals with the $T C$ or $C C$ genotypes of 

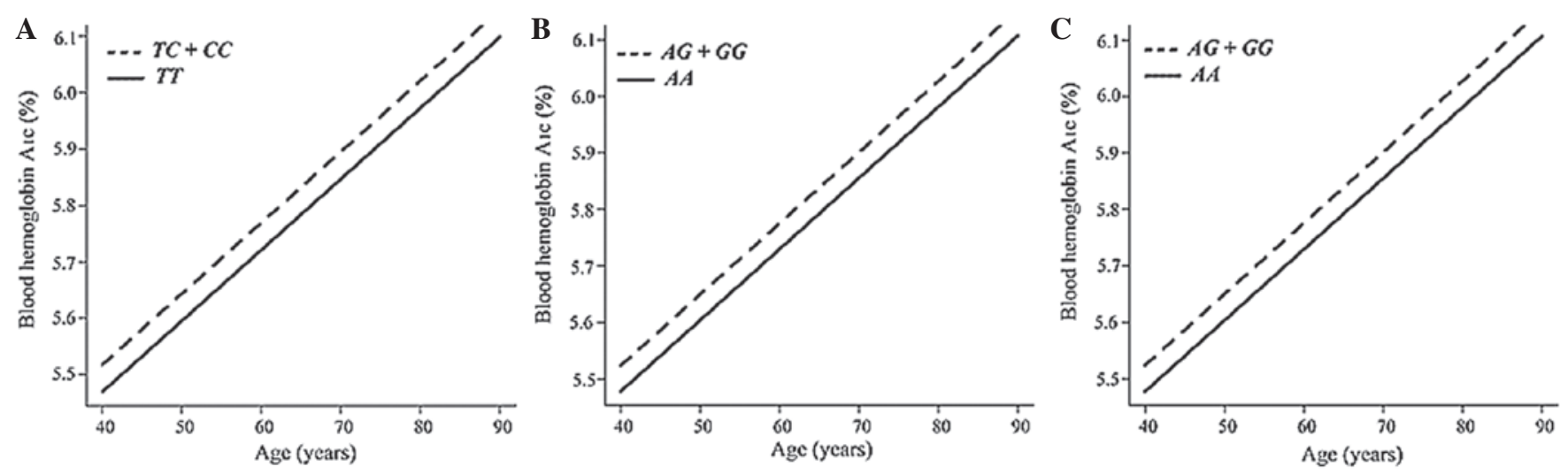

Figure 3. Longitudinal analysis of the associations between blood hemoglobin $\mathrm{A}_{\mathrm{lc}}$ content and age according to the genotype for (A) rs 2116519 of $F A M 78 B$ ( $T T+T C$ vs. $C C$ ), (B) rs2074379 of $A L P K 1$ ( $A A$ vs. $A G+G G$ ) or (C) rs2074388 of $A L P K 1$ ( $A A$ vs. $A G+G G$,), with a generalized linear mixed-effect model among all the individuals.

rs2116519 of $F A M 78 B$ compared to those with the $T T$ genotype from 40 to 90 years of age (Fig. 2A), in the combined group of individuals with the $A G$ or $G G$ genotypes of rs2074379 of $A L P K 1$ compared to those with the AA genotype (Fig. 2B) and in the combined group of individuals with the $A G$ or $G G$ genotypes of rs 2074388 of $A L P K 1$ compared to those with the $A A$ genotype (Fig. 2C).

The associations between blood hemoglobin $\mathrm{A}_{\mathrm{lc}}$ content and age analyzed longitudinally according to genotype in all the individuals with a generalized linear mixed-effect model are shown in Fig. 3. Blood hemoglobin $A_{1 c}$ was greater in the combined group of individuals with the $T C$ or $C C$ genotypes of rs2116519 of FAM78B compared to those with the $T T$ genotype from 40 to 90 years of age (Fig. 3A), in the combined group of individuals with the $A G$ or $G G$ genotypes of rs2074379 of $A L P K 1$ compared to those with the $A A$ genotype (Fig. 3B) and in the combined group of individuals with the $A G$ or $G G$ genotypes of rs 2074388 of $A L P K 1$ compared to those with the $A A$ genotype (Fig. 3C).

\section{Discussion}

As genetic factors and interactions between multiple genes and environmental factors are important in the development of type $2 \mathrm{DM}(1,7)$, prediction of the risk for type $2 \mathrm{DM}$ on the basis of genetic variants would be beneficial for personalized prevention of this condition. In the present study, rs2074379 and rs2074388 of $A L P K 1$ were significantly associated with the prevalence of type $2 \mathrm{DM}$ in a longitudinal genetic epidemiological study, with the minor $G$ allele of each SNP representing a risk factor for this condition. Our previous study showed that $A L P K 1$ is a susceptibility locus for chronic kidney disease in individuals with DM by a GWAS (20). We also observed that genetic variants of $A L P K 1$ were associated with type $2 \mathrm{DM}$ in a previous cross-sectional analysis of the Inabe Health and Longevity Study (28). The present results in the longitudinal population-based study are consistent with the previous observations in the cross-sectional study (28) and they validate the association of genetic variants of $A L P K 1$ with type 2 DM.

ALPK1 functions in apical transport by phosphorylating myosin 1a in epithelial cells and is indicated in the regulation of intracellular trafficking processes by phosphorylation (38).
ALPK1 may act synergistically with monosodium urate monohydrate crystals to promote the production of proinflammatory cytokines through the activation of nuclear factor- $\kappa \mathrm{B}$ and mitogen-activated protein kinase (extracellular signal-regulated kinase 1/2 and p38) signaling in cultured HEK293 cells, suggesting that ALPK1 may contribute to the inflammatory process associated with the development of gout (39).

Impaired insulin secretion and increased insulin resistance are key components of type $2 \mathrm{DM}$ (40). Although the contributions of these factors to the onset and progression of type 2 DM may differ between Caucasian and Asian populations, the two factors are significant for diagnostic and therapeutic strategies targeted to this disease (41). Previous studies have shown that proinflammatory cytokines (interleukin- $1 \beta$ and tumor necrosis factor) detrimentally affect insulin secretion and resistance $(42,43)$. Additionally, signaling pathways activated by proinflammatory cytokines, including those mediated by nuclear factor- $\kappa \mathrm{B}$, have been identified to impair insulin secretion or to promote insulin resistance (44). As chronic inflammation may play an important role in the development of type 2 DM, the effects of rs2074379 and rs2074388 of $A L P K 1$ on the inflammatory process may account for the association of this gene with type 2 DM.

rs 2116519 of $F A M 78 B$ was also associated with the prevalence of type $2 \mathrm{DM}$, as well as to fasting plasma glucose level and blood hemoglobin $\mathrm{A}_{\mathrm{lc}}$ content among all the individuals or to blood hemoglobin $\mathrm{A}_{1 \mathrm{c}}$ content among the individuals not taking antidiabetic medication. FAM78B is located at chromosome 1q24.1, a region previously suggested to harbor a susceptibility locus for type 2 DM (45), although the function of this gene remains unclear.

There are certain limitations to the present study: i) As the results were not replicated, validation of these findings requires their replication with other independent subject panels or ethnic groups; ii) rs2074379 or rs2074388 are possibly in linkage disequilibrium with other polymorphisms in the same gene or in other nearby genes that are responsible for the development of type $2 \mathrm{DM}$; and iii) the functional relevance of rs 2074379 or rs 2074388 of $A L P K 1$ to the pathogenesis of type $2 \mathrm{DM}$ has not been determined.

In conclusion, the present results suggest that $A L P K 1$ is a susceptibility gene for type $2 \mathrm{DM}$ in community-dwelling 
Japanese individuals. Determination of genotypes for the polymorphisms of ALPK1 may prove informative for assessment of the genetic risk for type $2 \mathrm{DM}$ in the Japanese population.

\section{Acknowledgements}

The present study was supported by Core Research for Evolutional Science and Technology of the Japan Science and Technology Agency (Y.Y. and I.T.) and by a Grant-in-Aid for Scientific Research from the Ministry of Education, Culture, Sports, Science and Technology of Japan (grant no. 24590746 to Y.Y.).

\section{References}

1. Stumvoll M, Goldstein BJ and van Haeften TW: Type 2 diabetes: Principles of pathogenesis and therapy. Lancet 365: 1333-1346, 2005.

2. Shaw JE, Sicree RA and Zimmet PZ: Global estimates of the prevalence of diabetes for 2010 and 2030. Diabetes Res Clin Pract 87: 4-14, 2010.

3. Chan JC, Malik V, Jia W, Kadowaki T, Yajnik CS, Yoon KH and Hu FB: Diabetes in Asia: Epidemiology, risk factors, and pathophysiology. JAMA 301: 2129-2140, 2009.

4. Yang W, Dall TM, Halder P, et al: Economic costs of diabetes in the U.S. in 2012. Diabetes Care 36: 1033-1046, 2013.

5. Zhang P, Zhang X, Brown J, Vistisen D, Sicree R, Shaw J and Nichols G: Global healthcare expenditure on diabetes for 2010 and 2030. Diabetes Res Clin Pract 87: 293-301, 2010.

6. Expert Committee on the Diagnosis and Classification of Diabetes Mellitus: Report of the expert committee on the diagnosis and classification of diabetes mellitus. Diabetes Care 26 (Suppl 1): S5-S20, 2003.

7. Hu FB: Globalization of diabetes: The role of diet, lifestyle, and genes. Diabetes Care 34: 1249-1257, 2011.

8. Wellcome Trust Case Control Consortium: Genome-wide association study of 14,000 cases of seven common diseases and 3,000 shared controls. Nature 447: 661-678, 2007.

9. Sladek R, Rocheleau G, Rung J, et al: A genome-wide association study identifies novel risk loci for type 2 diabetes. Nature 445 : 881-885, 2007.

10. Steinthorsdottir V, Thorleifsson G, Reynisdottir I, et al: A variant in CDKAL1 influences insulin response and risk of type 2 diabetes. Nat Genet 39: 770-775, 2007.

11. Bouatia-Naji N, Bonnefond A, Cavalcanti-Proença C, et al: A variant near MTNR1B is associated with increased fasting plasma glucose levels and type 2 diabetes risk. Nat Genet 41 : 89-94, 2009.

12. Voight BF, Scott LJ, Steinthorsdottir V, et al: Twelve type 2 diabetes susceptibility loci identified through large-scale association analysis. Nat Genet 42: 579-589, 2010.

13. Yasuda K, Miyake K, Horikawa Y, et al: Variants in KCNQ1 are associated with susceptibility to type 2 diabetes mellitus. Nat Genet 40: 1092-1097, 2008.

14. Unoki H, Takahashi A, Kawaguchi T, et al: SNPs in KCNQ1 are associated with susceptibility to type 2 diabetes in East Asian and European populations. Nat Genet 40: 1098-1102, 2008.

15. Yamauchi T, Hara K, Maeda S, et al: A genome-wide association study in the Japanese population identifies susceptibility loci for type 2 diabetes at UBE2E2 and C2CD4A-C2CD4B. Nat Genet 42: 864-868, 2010.

16. Cho YS, Chen $\mathrm{CH}, \mathrm{Hu} \mathrm{C}$, et al: Meta-analysis of genome-wide association studies identifies eight new loci for type 2 diabetes in east Asians. Nat Genet 44: 67-72, 2012.

17. Kooner JS, Saleheen D, Sim X, et al: Genome-wide association study in individuals of South Asian ancestry identifies six new type 2 diabetes susceptibility loci. Nat Genet 43: 984-989, 2011.

18. Yamada Y, Nishida T, Ichihara S, et al: Association of a polymorphism of BTN2A1 with myocardial infarction in East Asian populations. Atherosclerosis 215: 145-152, 2011.

19. Yamada Y, Fuku N, Tanaka M, et al: Identification of CELSR1 as a susceptibility gene for ischemic stroke in Japanese individuals by a genome-wide association study. Atherosclerosis 207: $144-149,2009$.
20. Yamada Y, Nishida T, Ichihara S, et al: Identification of chromosome 3q28 and ALPK1 as susceptibility loci for chronic kidney disease in Japanese individuals by a genome-wide association study. J Med Genet 50: 410-418, 2013.

21. Yamada Y, Matsuo H, Segawa T, et al: Assessment of genetic risk for myocardial infarction. Thromb Haemost 96: 220-227, 2006.

22. Fujimaki T, Kato K, Yoshida T, et al: Association of genetic variants with myocardial infarction in Japanese individuals with chronic kidney disease. Thromb Haemost 101: 963-968, 2009.

23. Oguri M, Kato K, Yokoi K, et al: Association of genetic variants with myocardial infarction in Japanese individuals with metabolic syndrome. Atherosclerosis 206: 486-493, 2009.

24. Go AS, Mozaffarian D, Roger VL, et al: Heart disease and stroke statistics - 2014 update: A report from the American Heart Association. Circulation 129: e28-e292, 2014.

25. Sacco RL, Benjamin EJ, Broderick JP, et al: American Heart Association Prevention Conference. IV. Prevention and Rehabilitation of Stroke. Risk factors. Stroke 28: 1507-1517, 1997.

26. Yamagata K, Ishida K, Sairenchi T, Takahashi H, Ohba S, Shiigai T, Narita M and Koyama A: Risk factors for chronic kidney disease in a community-based population: A 10-year follow-up study. Kidney Int 71: 159-166, 2007.

27. Yamada Y, Matsui K, Takeuchi I, Oguri M and Fujimaki T: Association of genetic variants with hypertension in a longitudinal population-based genetic epidemiological study. Int $\mathrm{J}$ Mol Med (In press).

28. Shimokata S, Oguri M, Fujimaki T, Horibe H, Kato K and Yamada Y: Association between polymorphisms of the $\alpha$-kinase 1 gene and type 2 diabetes mellitus in community-dwelling individuals. Biomed Rep 1: 940-944, 2013.

29. Ueyama C, Horibe H, Fujimaki T, Oguri M, Kato K and Yamada Y: Association of genetic variants of CELSR1 and 3q28 with hypertension in community-dwelling individuals. Biomed Rep 1: 840-844, 2013

30. Oguri M, Fujimaki T, Horibe H, Kato K, Ichihara S and Yamada Y: Association of a polymorphism of BTN2A1 with chronic kidney disease in community-dwelling individuals. Biomed Rep 1: 868-872, 2013.

31. Fujimaki T, Horibe H, Oguri M, Kato K and Yamada Y: Association of genetic variants of the $\alpha$-kinase 1 gene with myocardial infarction in community-dwelling individuals. Biomed Rep 2: 127-131, 2014

32. Horibe H, Ueyama C, Fujimaki T, Oguri M, Kato K, Ichihara S and Yamada Y: Association of a polymorphism of BTN2Al with dyslipidemia in community-dwelling individuals. Mol Med Rep 9: 808-812, 2014.

33. Murakata Y, Fujimaki T and Yamada Y: Association of a butyrophilin, subfamily 2 , member A1 gene polymorphism with hypertension. Biomed Rep 2: 818-822, 2014.

34. Kuzuya T, Nakagawa S, Satoh J, et al: Report of the Committee on the classification and diagnostic criteria of diabetes mellitus. Diabetes Res Clin Pract 55: 65-85, 2002.

35. Itoh Y, Mizuki N, Shimada T, Azuma F, Itakura M, Kashiwase K, Kikkawa E, Kulski JK, Satake M and Inoko H: High-throughput DNA typing of HLA-A, -B, -C, and -DRB1 loci by a PCR-SSOP-Luminex method in the Japanese population. Immunogenetics 57: 717-729, 2005.

36. Hanley JA, Negassa A, Edwardes MD and Forrester JE: Statistical analysis of correlated data using generalized estimating equations: An orientation. Am J Epidemiol 157: 364-375, 2003.

37. Dean CB and Nielsen JD: Generalized linear mixed models: A review and some extensions. Lifetime Data Anal 13: 497-512, 2007.

38. Heine M, Cramm-Behrens CI, Ansari A, Chu HP, Ryazanov AG, Naim HY and Jacob R: Alpha-kinase 1, a new component in apical protein transport. J Biol Chem 280: 25637-25643, 2005.

39. Wang SJ, Tu HP, Ko AM, Chiang SL, Chiou SJ, Lee SS, Tsai YS, Lee CP and Ko YC: Lymphocyte $\alpha$-kinase is a gout-susceptible gene involved in monosodium urate monohydrate-induced inflammatory responses. J Mol Med (Berl) 89: 1241-1251, 2011.

40. Kahn SE: The relative contributions of insulin resistance and beta-cell dysfunction to the pathophysiology of Type 2 diabetes. Diabetologia 46: 3-19, 2003.

41. Fukushima M, Usami M, Ikeda M, Nakai Y, Taniguchi A, Matsuura T, Suzuki H, Kurose T, Yamada Y and Seino Y: Insulin secretion and insulin sensitivity at different stages of glucose tolerance: A cross-sectional study of Japanese type 2 diabetes. Metabolism 53: 831-835, 2004. 
42. Ruotsalainen E, Salmenniemi U, Vauhkonen I, Pihlajamäki J, Punnonen K, Kainulainen S and Laakso M: Changes in inflammatory cytokines are related to impaired glucose tolerance in offspring of type 2 diabetic subjects. Diabetes Care 29: 2714-2720, 2006.

43. Olefsky JM and Glass CK: Macrophages, inflammation, and insulin resistance. Annu Rev Physiol 72: 219-246, 2010.
44. Norlin S, Ahlgren U and Edlund H: Nuclear factor- $\kappa$ B activity in $\beta$-cells is required for glucose-stimulated insulin secretion. Diabetes 54: 125-132, 2005.

45. Shriner D, Adeyemo A and Rotimi CN: Joint ancestry and association testing in admixed individuals. PLoS Comput Biol 7: e1002325, 2011. 